\title{
Application of Pipe Track Inner Mold Trolley Technology in Silver Pipe Track Project
}

\author{
Yuanxiang Jian* \\ China First Metallurgical Group Co., Ltd., China \\ *Corresponding author: Yuanxiang Jian, 272609340@qq.com
}

\begin{abstract}
This paper mainly introduces the research and application of the technical features, technological principles and construction procedures of the pipe track inner mold in the construction of the pipe track through the silver pipe track project. The inner mold system is composed of trolley support; with a combination of large mold instead of cabin mold scaffold system. The cabin mold scaffold system optimizes the cabin mold system construction from "scaffolding $\rightarrow$ installation mold $\rightarrow$ reinforcement $\rightarrow$ mold removal $\rightarrow$ scaffolding removal $\rightarrow$ horizontal transfer" to "inner mold trolley installation and commissioning $\rightarrow$ trolley in place $\rightarrow$ support form $\rightarrow$ release mold $\rightarrow$ mold movement." Reduce labor intensity, conserve construction consumables, and assure quality and safety by reducing the expansion, deconstruction, and transfer procedure of the mold and supporting structure. The occupation time of internal mold trolley in each structural construction section is reduced, the trolley turnover efficiency is improved, and the economic benefit is improved thanks to the central support of early mold removal in the workshop, which serves as a model for the construction organization and technical treatment of similar projects.
\end{abstract}

Keywords: Pipe track construction; Mold expansion; Inner mold trolley; Pipe track mold

Publication date: November 2021; Online publication: November 30, 2021

\section{Introduction}

With the rapid development of urban information industry, many information enterprises have established special information transmission networks. Most of these new information transmission networks use the existing power supply poles for overhead wiring, which cannot guarantee the safety and reliability, and seriously affect the city appearance and environment. Therefore, it is particularly important to build underground pipe corridors under urban roads. Generally, the construction of comprehensive pipe track mainly adopts pipe jacking, shield, open excavation prefabrication and hoisting, open excavation and castin-situ and other methods. At present, most of the pipe corridors mainly adopt the open excavation cast-insitu construction technology. This construction method can operate in a large area and divide the whole project into multiple construction sections, so as to speed up the construction progress. At the same time, this construction method has small technical difficulty, relatively low project cost and guaranteed construction quality. However, in the construction of each section of pipe track, internal and external mold construction, scaffold and support construction, disassembly and transfer are required. The amount of disassembly and assembly is large, requiring a lot of labor, which result in low construction efficiency and unstable quality. According to the silver comprehensive pipe track, three compartment or four compartment reinforced concrete underground box structure is adopted, including thermal cabin, natural gas cabin, power cabin and comprehensive cabin, including 7 comprehensive pipe tracks of North Loop Road, Yinshan Road, South Loop Road, Chengxin Avenue, Beijing Road, Yingbin Avenue and South Loop West Road, with a total length of about $26.25 \mathrm{~km}$. According to the characteristics of linear horizontal layout of each pipe track, 
tight construction period and large amount of repeated construction procedures, it is particularly necessary to design an intelligent mold trolley with high construction efficiency, small amount of disassembly and assembly, low labor intensity of workers and stable quality of cast-in-place construction of pipe track. Intelligent mold trolley has become a new development trend, which is of great significance to the automation of pipe track construction. Through the example of silver pipe gallery project, this paper discusses the technical characteristics, process principle, construction process and construction method of the mold in the pipe gallery, and provides reference for similar projects in the future.

\section{Project overview}

Baiyin underground comprehensive pipe track construction project is located in Baiyin District, Baiyin City, Gansu Province. The pipe gallery adopts three compartment or four compartment reinforced concrete underground box structure, including thermal compartment, natural gas compartment, power compartment and comprehensive compartment. The natural gas tank (natural gas pipeline) and power tank (above $100 \mathrm{kV}$ ) are separately divided into tanks, and the thermal tank and comprehensive tank are respectively arranged with thermal pipeline, power pipeline, communication pipeline, urban water supply pipeline, urban sewage pipeline, etc.

The pipe gallery system is arranged according to the mode of "double environmental control centers, branches, companies and clusters", and the total length of the proposed comprehensive pipe gallery is about $77.15 \mathrm{~km}$, with 1 control center and 38 substation. The pilot project includes 7 comprehensive pipe galleries, including North Loop Road, Yinshan Road, South Loop Road, Chengxin Avenue, Beijing Road, Yingbin Avenue and South Loop West Road, with a total length of about $26.25 \mathrm{~km}$. Combining the separate control of pipe gallery and centralized control of control center, and based on GIS information human-computer interaction interface, timely information exchange and sharing can be realized, which is integrated with the smart city, and a variety of monitoring fire automatic alarm and fire linkage systems can be organically integrated to achieve unified management and control.

\section{Technical proposal}

\subsection{Design of inner mold trolley}

According to the actual structural size of the pipe track and the load distribution of each part, calculate the mechanical properties to be met by the main transmission mechanism of the vehicle and the size of the supporting rod of each part, determine the spatial location of important parts, and select the most appropriate steel type, structure and size. The main frame is composed of hollow square steel and channel steel to ensure large rigidity and high bearing capacity of the internal mold trolley structure. It can replace the scaffold as the mold support mechanism, and fix the mold support structure on the trolley structure to realize the integration of mold and support. According to the section size of the cabin, the integrated trolley or doublejointed trolley shall be selected; For cabins with a clear width of less than $2 \mathrm{~m}$, an integrated trolley shall be used, and for cabins with a width of more than $2 \mathrm{~m}$, a double-jointed trolley shall be used. A central support is set in the middle of the double-jointed trolley, and multiple trolleys are assembled to form an integral internal mold. When the trolley is in the traveling state, the mold and trolley shall be reserved about $100 \mathrm{~mm}$ away from the cabin structure to facilitate walking. The trolley frame is equipped with supporting transmission device and relevant operation box. The trolley structure mainly uses square pipe structure, and the connection is fixed and connected with high-strength bolts. The mold and trolley are manufactured in an integrated structure, operated by mechanical transmission, demolded by the combination of mechanical power and self-weight, and hinged connection is adopted between the mold and the support system to facilitate the expansion and folding of the mold and ensure the trolley to walk in the pipe track; Frame structures such as trolley beams and columns are assembled with standard members to form equipment and 
standardization. When the trolley works, put down the support seat so that the roller leaves the ground without pressure. At the same time, use the support seat to adjust the level and verticality of the trolley. When the trolley moves, put up the support seat. The traveling mechanism adopts the motor reducer drive system to push the roller forward.

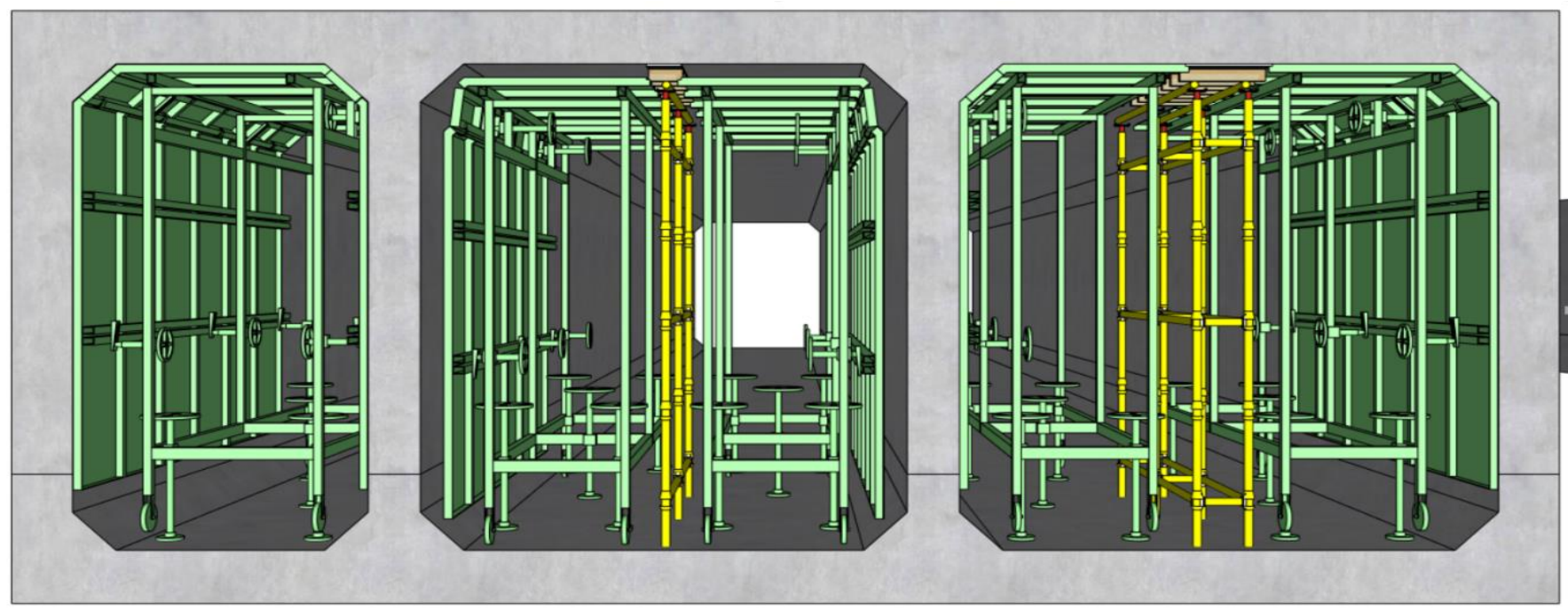

Figure 1. Scheme diagram of double-jointed trolley with early demolition template

\subsection{Specific implementation methods}

According to the construction status of silver pipe track, it is mainly implemented in the underground comprehensive pipe track section of Chengxin Avenue. The specific implementation steps are as follows: Pipe track bottom plate construction - pipe track wall reinforcement and embedded parts installation - mold trolley lifting into the pipe track - mold system moving to the corresponding pouring place - mold installation and reinforcement of mold system - pipe track roof reinforcement construction - wall and roof concrete pouring - mold system demolding - mold system moving to the lower pouring point.

\subsubsection{Construction of pipe track bottom plate}

The construction of pipe track bottom plate is the pre process of concrete construction of pipe track trolley mold system, and it is also the key to whether the mold system can move smoothly. Before the construction of bottom plate concrete, the foundation shall be treated to ensure that the foundation meets the strength required by the design, ensure the smooth movement of mold system, and the pouring of bottom plate concrete shall be smooth, especially during the pouring of floor corner concrete, attention shall be paid to controlling the structural size of the wallboard to prevent the mold expansion from affecting the installation speed of the mold trolley. For the pipe support to be poured on the bottom plate, it is best to use secondary pouring in order to facilitate the movement of the mold system. After the pouring of the bottom plate is completed, the mold shall be removed, the concrete flatness of the haunch corner shall be checked and polished, and the construction joint shall be roughened and cleaned.

\subsubsection{Installation of reinforcement and embedded parts of pipe track wallboard}

Curing shall be carried out after the construction of the bottom plate, and the installation of pipe track wall reinforcement and embedded parts can be carried out at the same time. This process starts from the position of the first poured bottom plate to ensure that the concrete strength of the bottom plate is not affected. Rebar and embedded parts are made in the factory and transported to the site. For $\varphi 14-16$ steel bar, flash butt welding is used, and $\varphi 20$ and above steel bar is connected by straight thread. Before installing the steel bar, pay attention to whether the steel bar reinspection and steel bar joint inspection are qualified, and whether 
the cutting size is consistent with the drawing. The wall reinforcement is double layer steel mesh, in order to ensure the thickness of the wall and the thickness of the steel protection layer, the steel bar hook is set between the steel mesh, the steel skeleton is fixed by the pull rod, and the embedded parts are connected and fixed with the L-shaped steel mesh. When necessary, the contact surface of the embedded parts and the template is set with fastening screws to ensure the position of the embedded parts. The steel bar, casing and embedded parts on the wall panel should be installed in place. For the embedded parts that need to be fixed with the template, they should be fixed when the vehicle model frame is divided into compartments. This process and the previous process are used as the previous process for the mold transfer and pouring of the pipe track trolley mold system, and the construction shall be carried out in sections with the flow rhythm.

\subsubsection{The mold trolley moves to the pouring point}

Firstly, according to the actual size of the cabin, select the mold system to enter the site. The cabin with net width $\leq 2 \mathrm{~m}$ adopts the integrated "door" trolley mold; Cabin with $2 \mathrm{~m}<$ the net width of the cabin body $\leq 6 \mathrm{~m}$, using " \ulcorner\urcorner ” type double jointed trolley frame, the central support set in the middle of double-jointed trolley, and central support uses tool template and stereotype template. When the concrete strength of pipe track bottom plate reaches to run the mold system and reaches $70 \%$, the mold system can be hoisted into the pipe track. In the hoisting process of the mold frame system, the hoisting port should be selected according to the geographical location first. According to the actual situation, the hoisting position of the construction section of Chengxin Avenue should be selected at the inspection port. The lifting position of the foundation should have a certain bearing capacity, lifting bearing beam (pole), according to the weight of the mold system to roughly calculate the bearing capacity, bearing beam at both ends should be enough beyond the length of the mold system, as far as possible horizontal lifting into the pipe corridor. In the process of hoisting, all the power lines of the motors should be wrapped to avoid the ground pressure line and tripping to ensure safety. The direction of the extension line of the pipe gallery should be assembled by the multisection car model frame. Every time the hoisting enters a section, move forward one section until the required platform length is reached. According to the size of the pipe gallery, basically $10 \mathrm{~m}$ is a section.

\subsubsection{Installation of mold trolley system in place}

After entering the site, the trolley mold system shall be assembled in sections. After assembly, the commissioning and trial operation of walking, mold expansion, mold removal and other processes shall be carried out. After the sectional commissioning of the trolley mold system, enter the pouring position of the first section of the pipe track. The bottom plate structure at the pouring position shall have a strength of more than $\mathrm{C} 20$, the structural size of the lower section of the wallboard shall meet the specification requirements, and the parts with deformation and mold expansion shall be treated first. Adjust the limit switch of the mold support device according to the size of the pipe track, so that the wallboard mold, corner tucking mold and roof are in the position of standard section size.

After the trolley mold system is in place, the trolley mold support shall be carried out in sections. According to the trolley mold system, first locate the mold system, adjust the trolley support device to make the top mold of the trolley mold system in the mold support position, then start the support device at the wallboard, put the wallboard mold and corner mold in the mold support position, and then carry out the mold support of the next trolley mold. Until the mold expansion of this cabin is completed, the trolley mold expansion of the next cabin shall be carried out. During this period, the embedded parts to be fixed shall be finally fixed before mold sealing. During the connection of multi trolley mold, the problems such as joint misalignment and gap shall be controlled. After fixing the trolley mold of all cabins, install the outer wall plate mold, the central mold between trolley mold and the mold of special openings, and bind the reinforcement of the top plate of the pipe track at the same time. Then reinforce the trolley mold and outer 
mold.

\subsubsection{Roof reinforcement construction}

According to the design drawings, the reinforcement is double-layer reinforcement mesh, mainly welded. The reinforcement is made and formed in the processing site, and then transported to the construction site according to the installation sequence. The blanking of reinforcement is batched by BIM, which well ensures the maximum utilization rate of materials. During the installation process, the bottom reinforcement is installed first, and then the surface reinforcement and reinforcement mesh (the bottom reinforcement and the surface reinforcement) is layered with the steel support, the support can be welded or tied, to ensure the spacing between the steel bars. When the bottom plate reinforcement is installed, the $30 \mathrm{~mm}$ protective layer cushion block shall be installed in place at any time. At least 1 or 2 of the joints of reinforcement shall be staggered at the same section. During the installation of reinforcement, attention shall be paid not to step on the reinforcement. When the reinforcement bar is installed, personal pedal should be placed. The pedal shall move with the installation position. Do not step directly on the reinforcement mesh, so as to prevent the size between the meshes from changing and ensure the cleanliness of the reinforcement surface. The reinforcement shall be installed along the flow operation surface.

\subsubsection{Concrete pouring of wall and roof}

Before concrete pouring, clean the garbage, sundries and oil stains on the mold and reinforcement, and then start pouring. Before pouring concrete, the ratio and slump of concrete shall be checked with the vehicle. At the same time, concrete specimens with the same conditions and standard curing shall be made at the pouring site. The concrete of pipe gallery shall be impermeable concrete. At the same time, specimens for impermeability inspection shall be made to test the strength of concrete at any time. The curing test blocks of the same article will be used as the basis for the mold removal time of mold system. The pouring sequence is the wall panel and then the top panel. Water stop steel plate and external water stop belt shall be set at the construction joint as required. Firstly, concrete with half stone is used at the joint to pour a slurry layer no more than $30 \mathrm{~mm}^{[1]}$ thick, and then the wallboard concrete shall be poured. The walls on both sides shall be symmetrical at the same time. During the concrete pouring, special personnel shall be arranged to make the concrete test block and inspect the slump; Assign special personnel to observe the mold and reinforcement at the pouring point to avoid accidents. When pouring concrete, it is forbidden to directly lay ash against the embedded parts, and the vibrating rod shall not collide with the embedded parts, fixed frames and tension pieces. The layered thickness of concrete pouring shall be controlled within $500 \mathrm{~mm}$, and the layered pouring shall be carried out according to the gradient of 1:6 1:10, and the upper concrete shall cover the lower concrete for more than $500 \mathrm{~mm}$ in advance. When construction joints are not allowed, the pouring interval time between areas and between upper and lower layers shall not exceed the initial setting time of concrete. When the plug-in vibrator is used to vibrate the concrete, the vibrator shall be "inserted quickly and pulled out slowly", and the falling point shall be uniform. The vibration time shall be subject to the fact that the concrete surface will not sink and the surface is flooded with slurry. The insertion spacing is $300 \mathrm{~mm}$, arranged in a quincunx shape, and the insertion depth is $50-100 \mathrm{~mm}$ into the lower layer. It is strictly prohibited to add water to the concrete randomly during pouring, and special attention shall be paid to the vibration between the upper and lower layers of concrete, joints and dense parts of reinforcement, so as to ensure the compactness of concrete vibration.

\subsubsection{The trolley mold system demolds and walks to the next section}

When the concrete strength of the wall roof reaches $50 \%{ }^{[1]}$ after pouring, the mold shall be removed. For cabins with a width greater than $2 \mathrm{~m}$, the central support system shall be used to cooperate with the trolley 
mold to remove the trolley mold and walk to the next section.

\subsection{Quality requirements}

According to "Code for Acceptance of Construction Quality of Concrete Structure Engineering (GB502042015)" [1] and "Code for Construction of Concrete Structure Engineering (GB50666-2011)" [2], the acceptance requirements for mold expansion of internal mold trolley are shown in Table 1.

Table 1. Allowable deviation and inspection method for mold expansion of internal mold trolley ${ }^{[2]}$

\begin{tabular}{clcl}
\hline Number & \multicolumn{1}{c}{ Project } & $\begin{array}{c}\text { Allowable } \\
\text { deviation mm }\end{array}$ & \multicolumn{1}{c}{ Inspection method } \\
\hline 1 & Axis position & 5 & Ruler measurement \\
2 & Elevation of upper surface of bottom mold & \pm 5 & Stay wire, ruler or level gauge \\
3 & Internal dimension of mold (wall) & \pm 5 & Ruler measurement \\
4 & Perpendicularity of wallboard mold & 6 & Ruler measurement \\
5 & Surface elevation difference of trolley & 2 & Ruler measurement \\
& mold and central support mold & & 2m guiding rule feeler gauge \\
6 & Surface flatness & 5 &
\end{tabular}

\subsection{Quality control measures}

According to the characteristics of the mold trolley and in order to better ensure the construction of concrete to achieve the effect of clean concrete, in the construction process, the first is to ensure the flatness of the foundation floor in the construction process. The mold trolley can be hoisted into the pipe gallery only after the concrete of bottom slab reaches 21 days. After the assembly of the mold trolley, the jacking and limit test of the roof and wall panel should be carried out to check whether the size and the flexibility of jacking equipment and limit switch can meet the requirements of the design drawings. Before the template is hoisted into the pipe track, the roof and wall panels should be evenly coated with demolding agent. In order to ensure the quality of concrete, before brushing the release agent, clean the template fully and then brush the oily release agent. After each construction, it is necessary to check the surface smoothness of the template to ensure the demolding effect of the template during the whole construction process

Before the trolley enters the track, the flatness of the haunch angle of the concrete base plate shall be checked. In order to ensure the tightness of the combination of wallboard concrete and base plate concrete, the whole haunch angle of the bottom plate shall be measured and cleaned before the trolley mold enters the track. The uneven haunch angle shall be polished to ensure that the trolley mold is closely connected with the concrete surface of the haunch angle. After the mold is jacked to the position required by the design, check each jacking screw rod of the mold to see if it has been jacked tightly. The joint position of the two mold trolleys must ensure that the two trolleys are on a horizontal plane. When connecting, pay attention to whether the connecting bolts are in place or have deformation and dislocation. During the installation of the top axillary corner mold, attention must be paid to cleaning to prevent slag inclusion and other phenomena, so as to avoid leakage of grout, resulting in unsightly axillary corners after demolding.

\subsection{Safety precautions}

Due to the different construction loads caused by different sizes and different construction environments, before using the existing mold trolley, according to the structural selection of the trolley, and comprehensively considering the self-weight of on-site personnel, equipment, materials and concrete vibration, the stress safety calculation of each part of the trolley is carried out to ensure that the mold trolley 
has sufficient bearing capacity.

The bending strength ${ }^{[3]} \sigma=\frac{m_{\max }}{w_{n}} \leq f$ and deflection ${ }^{[3]} v=\frac{5 q_{g} L^{4}}{384 E I_{x}}+\frac{P L^{3}}{48 E I_{x}} \leq[v]$ of beams and plates shall be checked; The strength ${ }^{[4]} \mathrm{A}=\frac{F}{[\sigma]}$ and stability of columns and inclined supports shall be checked and calculated during axial tension or compression.

\section{Conclusions and recommendations}

The inner mold trolley has been applied in the underground comprehensive pipe gallery project of Chengxin Avenue in Baiyin City, and achieved good results. It has effectively shortened the mold construction period, reduced the manual workload in mold expansion, mold removal and transportation by more than $70 \%$. At the same time, the concrete structure has good quality and reduced the manual investment in subsequent repair work. It can be used for rectangular box structure with tucked corners, and can be used in municipal pipe gallery, hydraulic box culvert, underpass and other projects. Based on the internal mold trolley, the mold moving pouring construction method is used instead of the internal mold and supporting scaffold construction in the pipe gallery. Multiple molds are combined into a whole through the hinge mechanism. During mold expansion and demolding, the procedures of mold expansion in place and demolding recovery are completed through successive operations. The lead screw is used for electric control of mold support, programmed operation is used for mold expansion and demolding, and equipment is formed, which greatly reduces the labor consumption of structural construction. It is in line with the development direction of China's construction industry towards refinement, equipment and industrialization.

\section{Disclosure statement}

The author declares no conflict of interest.

\section{References}

[1] 2011, Code for Construction of Concrete Structure Engineering (GB50666-2011), 19+116.

[2] 2015, Code for Acceptance of Construction Quality of Concrete Structure Engineering (GB502042015), 9.

[3] 2008, Technical Code for Safety of Building Construction mold (JGJ162-2008), 26+28.

[4] 2017, Design Code for Steel Structures (GB 50017-2017), 33. 